\title{
Emerging use of everolimus in the treatment of neuroendocrine tumors
}

This article was published in the following Dove Press journal:

Cancer Management and Research

20 June 2017

Number of times this article has been viewed

\author{
Pablo Gajate \\ Olga Martínez-Sáez \\ Teresa Alonso-Gordoa \\ Enrique Grande \\ Medical Oncology Department, \\ Ramon y Cajal University Hospital, \\ Madrid, Spain
}

Correspondence: Pablo Gajate

Medical Oncology Department, Ramon y Cajal University Hospital, Ctra. Colmenar Viejo, km 9100, 28029 Madrid, Spain Tel/fax+34 9l 3368263

Email pgajate@oncologiahrc.com

\begin{abstract}
Neuroendocrine tumors (NETs) consist of a diverse family of malignancies, which are derived from neuroendocrine cells, most commonly originating from the gastroenteropancreatic (GEP) tract or the bronchopulmonary system. In general, NETs are more indolent than epithelial tumors, with median survival rates of longer than 30 months. The upregulation of mTOR pathway has been shown to play a pivotal role in NET pathogenesis. Inhibition of mTOR protein with everolimus represents a progress in the treatment of advanced NETs. Everolimus has shown a significant improvement in progression-free survival (PFS) among patients with pancreatic NETs (pNETs) and nonfunctional GEP and lung NETs in the Phase III RAD001 in Advanced Neuroendocrine Tumors (RADIANT)-3 and RADIANT-4 studies, respectively. In addition, the combination of everolimus with octreotide showed a clinically significant improvement versus octreotide alone in functional NETs in the RADIANT-2 trial. These studies led to the US Food and Drug Administration (FDA) and European Medical Agency (EMA) approval of everolimus. Safety profile of everolimus is generally acceptable. The most common adverse events are stomatitis, diarrhea, rash and fatigue. There is a growing range of novel treatment options in the setting of NETs, but there are no data comparing the activity of different treatment strategies. Thus, treatment decisions are based on different aspects, such as clinical course, patient symptomatology, primary tumor site, tumor functionality, rate of progression and burden of disease. Further research is required to clarify the treatment sequencing to achieve the maximum prolongation in survival and maintenance of quality of life. Future research should concentrate on identification of predictive biomarkers for benefit from different therapies, and studies should also include quality of life as an important measurement in this disease.
\end{abstract}

Keywords: everolimus, mTOR inhibitor, pancreatic neuroendocrine tumors, gastrointestinal neuroendocrine tumors, systemic treatment

\section{Introduction to the management issues in the treatment of neuroendocrine tumors (NETs)}

Neuroendocrine neoplasms (NENs) are defined as epithelial tumors with predominant neuroendocrine differentiation. NENs can virtually arise in all organs of the body, although the majority originates from the gastroenteropancreatic (GEP) system or the bronchopulmonary tract. ${ }^{1}$

NENs can be classified into clinically relevant groups based primarily on their hormonal activity (functional or nonfunctional tumors), histological characteristics (proliferative index and grade of differentiation) and embryonic origin of primary site. ${ }^{1,2}$ However, the classification of NENs is complex because there is no one single 
nomenclature, grading or staging system that is suitable for all NENs from the different anatomic sites. In general, NENs are divided into well-differentiated and poorly differentiated categories. ${ }^{3}$ The European Neuroendocrine Tumor Society (ENETS) and the World Health Organization (WHO) 2010 classification systems for GEP NENs categorize tumors as well-differentiated NETs that can be divided into grade 1 and grade 2 depending on their proliferation rate (mitosis number and KI-67 labeling index) and poorly differentiated neuroendocrine carcinomas (NECs), grade 3.4-6 However, the ENETS recommendations for pulmonary carcinoids and the WHO 2015 classifications of lung and thymus NENs slightly differ. In addition to KI-67, they take into account the grade of necrosis and define three distinct subgroups: typical carcinoid, atypical carcinoid (that would correspond to NET grades 1 and 2, respectively) and large- and small-cell NECs (equivalent to grade 3; Table 1). ${ }^{7,8}$

Radical surgery is the only curative treatment for NETs, although other locoregional therapies, such as radiofrequency, are considered effectively as antitumor treatment and in relieving symptoms whenever resection is not possible..$^{9,10}$ The aim of therapy for patients with advanced NETs will be to achieve tumor control through eradicating or stabilizing disease, prolonging survival and relieving the symptoms of functional tumors, while maintaining the quality of life (QoL). Fortunately, over the past decade, different treatment options in the setting of metastatic disease have been evolving, which include systemic treatment with somatostatin analogs (SSAs), interferon- $\alpha$ (INF- $\alpha$ ), peptide receptor radiotargeted therapy (PRRT), cytotoxic chemotherapy or molecular target agents (Table 2). ${ }^{1-15}$ However, none of these approaches have been directly compared in randomized clinical trials, and therefore, there are still unresolved questions around which is the best treatment sequence. ${ }^{11-13,16}$ Therapeutic decisions are, at the moment, guided by clinical judgment, based on different parameters such as the primary site of the tumor, functionality, histology and grading, uptake on somatostatin receptor imaging, tumor burden and the presence of extrahepatic disease..$^{8,13}$

This review focuses on the role of everolimus, an mTOR inhibitor approved for the treatment of advanced pancreatic NETs (pNETs) and advanced nonfunctional gastrointestinal and lung NETs.

\section{Overview of pharmacology, mode of action, pharmacokinetics of everolimus in NETs}

mTOR is a serine/threonine kinase intermediary within the phosphoinositide 3-kinase (PI3K)-Akt pathway that recognizes stress signals (e.g., nutrient and energy depletion, oxidative or hypoxic stress and proliferative and survival signals) and regulates cell survival, proliferation and apoptosis (Figure 1). There are two multiprotein complexes: mTOR complex 1 (mTORC1) and mTOR complex 2 (mTORC2). ${ }^{17,18}$

Table I Nomenclature systems for GEP and lung/thymus NENs

\begin{tabular}{|c|c|c|c|c|c|c|}
\hline \multicolumn{4}{|l|}{ GEP NENs } & \multicolumn{3}{|c|}{ Lung and thymus } \\
\hline Grade & $\begin{array}{l}\text { Mitotic count } \\
\text { (mit/ / } 0 \text { HPF) }\end{array}$ & $\begin{array}{l}\text { KI-67 } \\
\text { index (\%) }\end{array}$ & $\begin{array}{l}\text { WHO/ENETS } \\
\text { nomenclature }\end{array}$ & $\begin{array}{l}\text { Mitotic count } \\
\left(\mathrm{mit} / 2 \mathrm{~mm}^{2}\right)\end{array}$ & Necrosis & $\begin{array}{l}\text { WHO/ENETS } \\
\text { nomenclature }\end{array}$ \\
\hline Low grade & $<2$ & $<3$ & NET, grade I & $<2$ & Absent & Carcinoid tumor \\
\hline $\begin{array}{l}\text { Intermediate } \\
\text { grade }\end{array}$ & $2-20$ & $3-20$ & NET, grade 2 & $2-10$ & $\begin{array}{l}\text { Foci of punctate } \\
\text { necrosis }\end{array}$ & $\begin{array}{l}\text { Atypical carcinoid } \\
\text { tumor }\end{array}$ \\
\hline High grade & $>20$ & $>20$ & $\begin{array}{l}\text { NEC, grade } 3 \text { (large- } \\
\text { cell or small-cell type) }\end{array}$ & $>10$ & $\begin{array}{l}\text { Extensive } \\
\text { geographic } \\
\text { necrosis }\end{array}$ & $\begin{array}{l}\text { Small-cell carcinoma } \\
\text { Large-cell NEC }\end{array}$ \\
\hline
\end{tabular}

Abbreviations: ENETS, European Neuroendocrine Tumor Society; GEP, gastroenteropancreatic; HPF, high power fields; Mit, mitoses; NEC, neuroendocrine carcinoma; NENs, neuroendocrine neoplasms; NET, neuroendocrine tumor; WHO, World Health Organization.

Table 2 Phase III trials in advanced NETs with systemic treatment other than everolimus

\begin{tabular}{|c|c|c|c|c|}
\hline Reference & Trial Phase & Study drugs & $\begin{array}{l}\text { Primary } \\
\text { tumor }\end{array}$ & PFS (months) \\
\hline Caplin et $\mathrm{al}^{71}$ & III & Lanreotide $120 \mathrm{mg}$ versus placebo & GEP NETs & NR versus I8.0; HR: $0.47 ; p<0.00$ I \\
\hline Rinke et al ${ }^{14}$ & III & Octreotide LAR 30 mg versus placebo & NETs & I4.3 versus $6.0 ; \mathrm{HR}: 0.34 ; p=0.000072$ \\
\hline Strosberg et al ${ }^{15}$ & III & ${ }^{177} \mathrm{Lu}$-Dotatate versus octreotide LAR $60 \mathrm{mg}$ & Midgut NETs & NR versus 8.4; HR: $0.21 ; p<0.001$ \\
\hline Raymond et $\mathrm{al}^{72}$ & III & Sunitinib versus placebo & pNETs & II .4 versus $5.5 ; \mathrm{HR}: 0.42 ; p<0.00 \mathrm{I}$ \\
\hline Sun et $\mathrm{al}^{73}$ & II/III & $\begin{array}{l}\text { Doxorubicin + fluorouracil versus } \\
\text { streptozocin + fluorouracil }\end{array}$ & NETs & 4.5 versus $5.3 ; p=0.17$ \\
\hline
\end{tabular}

Abbreviations: GEP, gastroenteropancreatic; HR, hazard ratio; LAR, long-acting repeatable; NET, neuroendocrine tumor; NR, not reached; PFS, progression-free survival; PNET, pancreatic NET. 


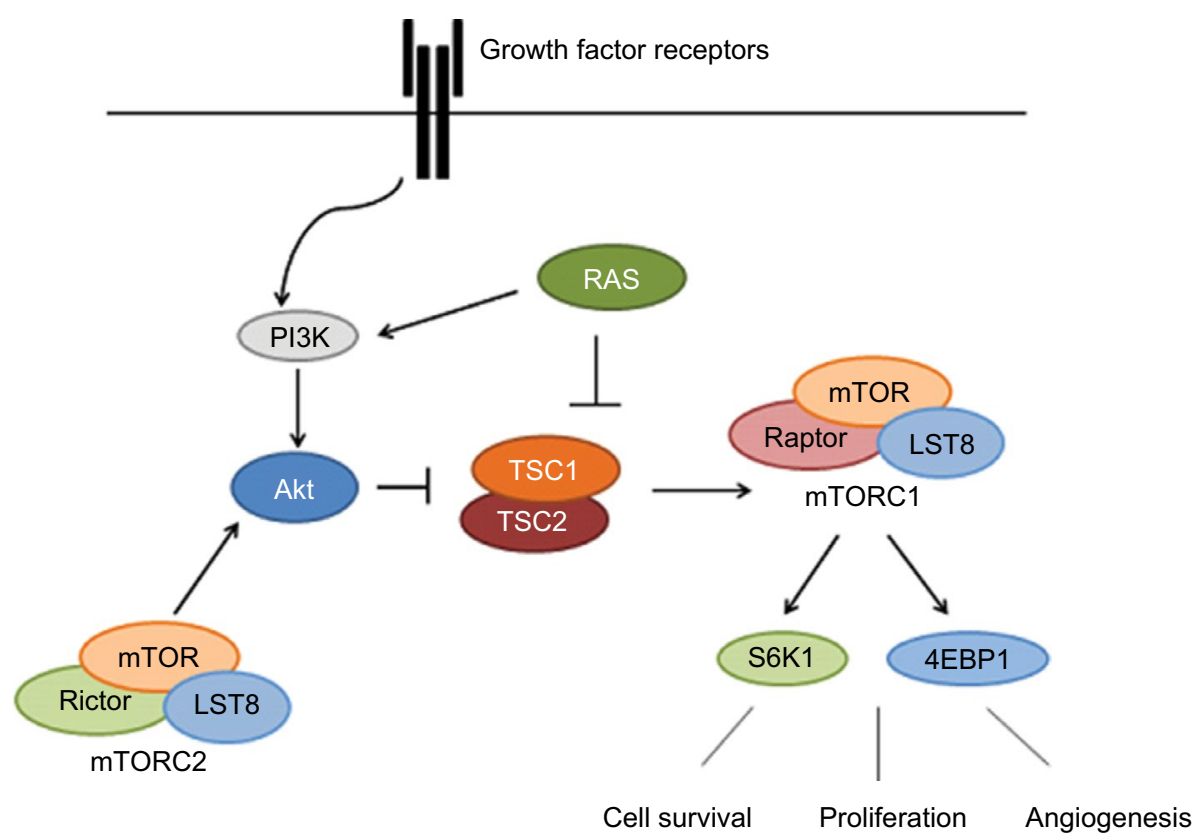

Figure I mTOR pathway.

Notes: $\mathrm{mTORCI}$ consists of $\mathrm{mTOR}$ associated with two proteins: regulatory-associated protein of $\mathrm{mTOR}$ (raptor) and target of rapamycin complex subunit LST8. $\mathrm{mTORC2}$ consists of mTOR and associated proteins: target of rapamycin complex subunit LST8 and rapamycin-insensitive companion of mTOR (rictor).

$\mathrm{PI} 3 \mathrm{~K} / \mathrm{Akt}$ signaling regulates mTOR through inactivation of tuberous sclerosis complex-2 (TSC2), a negative regulator of mTOR. mTORC1 activation results in phosphorylation of its effectors, 4EBP1 and S6K1, which enhance cell proliferation, survival and angiogenesis through the translation of cyclin D1, Bcl-2, Bcl-xL, hypoxia-inducible factor-1 (HIF-1) and VEGF. The role of mTORC2 is less well defined, but is known to directly phosphorylate Akt, leading to full Akt activation. ${ }^{19}$

PI3K/Akt signaling pathway has been shown to be deregulated in several human malignancies, including NETs, through several mechanisms, including overexpression or activation of growth factor receptors such as insulin-like growth factor receptor (IGFR), human epidermal growth factor receptor 2 (HER-2), mutations in PI3K and mutations/ amplifications of Akt. ${ }^{19-25}$ Ras/MAPK signaling can also inhibit TSC2 leading to mTOR activation. ${ }^{26}$

mTORC1 can be pharmacologically inhibited by the macrolide rapamycin. Rapamycin forms a complex with FK506-binding protein 12 (FKBP12), and this complex binds and inhibits mTORC1, leading to cell cycle arrest, inhibition of endothelial cell proliferation, HIF-1 and VEGF expression and angiogenesis. ${ }^{18,19,27}$ In contrast, mTORC2 is believed to be insensitive to rapamycin. However, it has been shown that prolonged rapamycin treatment reduces mTORC2 levels and inhibits Akt activation in some cell lines. ${ }^{19}$

Everolimus [Afinitor ${ }^{\mathbb{R}}$, RAD-001 (40-O-(2-hydroxyethyl)rapamycin)] is a rapamycin analog (rapalog) that has been developed to improve the pharmacokinetic characteristics of rapamycin, mostly its oral bioavailability. ${ }^{28-30}$

Oral everolimus is absorbed rapidly and achieves peak concentration $\left(C_{\max }\right)$ after 1-2 hours. Steady state is reached within 7 days. The steady-state peak, concentrations and area under the concentration-time curve (AUC) are proportional to dosage. In adults, everolimus pharmacokinetic characteristics do not differ according to age, weight or sex..$^{30}$ Everolimus is metabolized mainly by CYPP450, CYP3A4, 3A5 and 2C8 in the gut and liver. ${ }^{30,31}$ Approximately $98 \%$ of everolimus is excreted in the bile in the form of metabolites and $2 \%$ is excreted in the urine. The elimination half-life ranges from 18 to 35 hours. ${ }^{24,30,32,33}$

\section{Activity of everolimus in patients with NETs}

Everolimus has been shown to inhibit proliferation of different human solid tumors in preclinical studies. ${ }^{34-37}$ Several Phase II studies have shown a promising antitumor activity in advanced NETs of different anatomic sites (Table 3). ${ }^{38,39}$ Yao et $\mathrm{al}^{40}$ conducted a single institution, Phase II trial to evaluate the efficacy of everolimus 5 or $10 \mathrm{mg}$ /day in combination with octreotide long-acting repeatable (LAR) $30 \mathrm{mg}$ every 28 days in 60 patients with NETs of different anatomical locations. They showed a promising antitumor activity, with $22 \%$ of partial response (PR), $70 \%$ of stable disease (SD) and progression-free survival (PFS) of 60 weeks. 
Table 3 Combination studies with everolimus in patients with NETs

\begin{tabular}{|c|c|c|c|c|c|c|}
\hline Study & $\begin{array}{l}\text { Trial } \\
\text { phase }\end{array}$ & $\begin{array}{l}\text { Number of } \\
\text { patients }\end{array}$ & Study drugs & Primary tumor & Response & PFS (months) \\
\hline Chan et $\mathrm{al}^{38}$ & I & 22 & Everolimus + pasireotide & $\begin{array}{l}\text { GEP, lung or } \\
\text { unknown primary }\end{array}$ & $\begin{array}{l}90 \% \mathrm{SD}, 81 \% \text { some } \\
\text { degree of tumor } \\
\text { shrinkage }\end{array}$ & At 6 months: $76 \%$ \\
\hline Chan et $\mathrm{al}^{39}$ & I & 21 & Everolimus + sorafenib & $\begin{array}{l}\text { GEP, lung or } \\
\text { unknown primary }\end{array}$ & $6 \% \mathrm{PR}, 76 \% \mathrm{SD}$ & At 6 months: $79 \%$ \\
\hline Yao et $\mathrm{al}^{40}$ & II & 60 & $\begin{array}{l}\text { Everolimus } 5 \text { or } 10 \mathrm{mg}+ \\
\text { octreotide }\end{array}$ & $\begin{array}{l}\text { GEP, lung or } \\
\text { unknown primary }\end{array}$ & $22 \% \mathrm{PR}, 70 \% \mathrm{SD}$ & $\begin{array}{l}5 \mathrm{mg}: 10 \\
10 \mathrm{mg}: 14\end{array}$ \\
\hline $\begin{array}{l}\text { Yao et al }{ }^{41} \\
\text { (RADIANT-I) }\end{array}$ & II & 160 & $\begin{array}{l}\text { Everolimus + octreotide } \\
\text { versus everolimus }\end{array}$ & Pancreatic & $\begin{array}{l}10 \% \text { PR, } 68 \% \text { SD } \\
4 \% \text { PR, } 80 \% \text { SD }\end{array}$ & $\begin{array}{l}16 \\
9.7\end{array}$ \\
\hline Kulke et a ${ }^{61}$ & II & 150 & $\begin{array}{l}\text { Everolimus + octreotide + } \\
\text { bevacizumab } \\
\text { Everolimus + octreotide }\end{array}$ & Pancreatic & $\begin{array}{l}31 \% \mathrm{PR} \\
12 \% \mathrm{PR}\end{array}$ & $\begin{array}{l}16.7 \\
14\end{array}$ \\
\hline $\begin{array}{l}\text { Kulke et al }{ }^{59} \\
\text { (COOPERATE-II) }\end{array}$ & II & 160 & $\begin{array}{l}\text { Everolimus + pasireotide } \\
\text { Everolimus }\end{array}$ & Pancreatic & $\begin{array}{l}20 \% \mathrm{PR} \\
6 \% \mathrm{PR}\end{array}$ & $\begin{array}{l}16.6 \\
16.8\end{array}$ \\
\hline Ferolla et al ${ }^{74}$ (LUNA) & II & 124 & $\begin{array}{l}\text { Pasireotide } \\
\text { Everolimus } \\
\text { Everolimus + pasireotide }\end{array}$ & Lung/thymus & $\begin{array}{l}2 \% \text { PR, } 34 \% \text { SD } \\
2 \% \text { PR, } 31 \% \text { SD } \\
2 \% \text { PR, } 49 \% \text { SD }\end{array}$ & $\begin{array}{l}\text { At } 9 \text { months: } 39 \% \\
\text { At } 9 \text { months: } 33 \% \\
\text { At } 9 \text { months: } 56 \%\end{array}$ \\
\hline
\end{tabular}

Abbreviations: GEP, gastroenteropancreatic; NET, neuroendocrine tumor; PFS, progression-free survival; PR, partial response; SD, stable disease.

The encouraging results in this single-institution trial led to the development of a longer, multinational, singlearm, Phase II trial, RAD001 in Advanced Neuroendocrine Tumors (RADIANT)-1. This study assesses the efficacy of everolimus $10 \mathrm{mg} /$ day, with or without concomitant octreotide LAR $30 \mathrm{mg}$ in 160 patients with metastatic pNETs who had progressed after chemotherapy. Patients were stratified by prior SSAs (stratum 1: no prior SSAs and stratum 2: prior SSAs). Patients who had previously received SSAs were continued on these agents. The study showed antitumor activity as measured by overall response rate (ORR) and PFS. In stratum 1, PR was $10 \%$, SD was $68 \%$ and PFS was 9.7 months. In stratum 2, PR was $4 \%$, SD was $80 \%$ and median PFS was 16.7 months. The differences between the two groups were not statistically significant, although the study was not designed to evaluate whether combination therapy was superior to monotherapy. ${ }^{41}$

Due to the promising results of everolimus in these Phase II trials, several randomized, multicenter studies were carried out under the umbrella of the RADIANT program to analyze the efficacy of everolimus in advanced NETs (Table 4).

Pavel et $\mathrm{al}^{42}$ conducted the RADIANT-2 trial, an international, double-blind, Phase III study, that compared the efficacy of everolimus $10 \mathrm{mg}$ /day with placebo, both in conjunction with octreotide LAR $30 \mathrm{mg}$ every 28 days in advanced functional GEP and lung NETs. The study included 429 patients, and crossover to everolimus was allowed at disease progression. The trial showed an increase in PFS in patients receiving everolimus (16.4 versus 11.3 months; hazard ratio [HR]: $0.77 ; p=0.026)$, failing to reach the level of prespecified boundary for significance $(p \leq 0.0246)$. Despite the fact that the study did not meet its primary end point, the results provided an initial indication of the potential antitumor effect of everolimus in patients with NETs. No differences were observed in overall survival (OS) among the study arms, probably due to the high proportion of patients on the placebo arm crossed over to everolimus at disease progression $(58 \%))^{43}$

Yao et $\mathrm{a}^{44}$ conducted another Phase III study, the RADIANT-3, in 410 patients with advanced pNETs who were randomly assigned to monotherapy with everolimus $10 \mathrm{mg} /$ day or placebo, with also a double-blind crossover study design. As in the previous studies, ORR was low (5\%), but patients treated with everolimus had a significantly longer PFS (11.4 versus 5.4 months; HR: 0.34, $p<0.0001$ ). Prespecified subgroup analyses indicated that the benefit was maintained across subgroups, irrespective of prior chemotherapy or SSA therapy, performance status, age, sex, race, geographic region and tumor grade. After adjusting for crossover bias ( $85 \%$ of patients), the results showed a nonsignificant prolongation in median OS of 6.3 months with everolimus compared with placebo (44.0 versus 37.7 months; HR: 0.94; $p=0.3) .{ }^{45}$ In 2011, based on the results of RADIANT-3, the US Food and Drug Administration (FDA) and European Medical Agency (EMA) approved the use of everolimus for the treatment of progressive, advanced pNETs. ${ }^{46}$

RADIANT- $4{ }^{47}$ was a large placebo-controlled Phase III study, which evaluated the efficacy of monotherapy with 
everolimus $10 \mathrm{mg} /$ day versus placebo in 302 patients with advanced, nonfunctional, progressive gastrointestinal or lung NETs. The study showed a significantly prolonged median PFS by 7.1 months compared with placebo (11 versus 3.9 months; HR: $0.48 ; p<0.00001)$. Although not statistically significant, the results of the first preplanned interim OS analysis indicated that everolimus might be associated with a reduction in the risk of death (HR: $0.64 ; p=0.037$, whereas the boundary for statistical significance was 0.0002 ). A retrospective analysis also showed consistent beneficial effect across the subgroups based on primary tumor origin (lung, gastrointestinal or NETs of unknown primary origin). Based on these data, in 2016, everolimus received FDA and EMA approval for the treatment of patients with progressive, advanced, nonfunctional gastrointestinal (GI) and lung NETs. ${ }^{46}$

\section{Safety and tolerability: patient- focused perspectives such as QoL, patient satisfaction/acceptability, and adherence}

Everolimus presents an acceptable safety profile. The most common adverse events observed in the RADIANT-2, RADIANT-3 and RADIANT-4 trials were stomatitis, rash, diarrhea, fatigue, infections, nausea and peripheral edema (Table 5), but only a small percentage of patients, about 5-7\%, developed grade 3-4 toxicities. Drug-related pneumonitis, a well-known complication of everolimus, was reported in $8 \%$ of patients in RADIANT-2, $17 \%$ in RADIANT- 3 and $16 \%$ in RADIANT-4, with $1-2 \%$ of grades $3-4 .{ }^{42,44,47}$

Everolimus has been also shown to be safe in the realworld setting, as shown by a retrospective study conducted

Table 4 Phase III trials with everolimus in patients with NETs

\begin{tabular}{|c|c|c|c|c|c|}
\hline Study & $\begin{array}{l}\text { Number of } \\
\text { patients }\end{array}$ & Study drugs & Primary tumor & Response & PFS (months) \\
\hline Pavel et al ${ }^{42}$ & 429 & Everolimus + octreotide & Functional GEP or lung & $2.3 \% \mathrm{PR}, 82 \% \mathrm{SD}$ & 16.4 \\
\hline (RADIANT-2) & & Octreotide & & $1.9 \% \mathrm{PR}, 81 \% \mathrm{SD}$ & 11.3 \\
\hline Yao et $\mathrm{al}^{44}$ & 410 & Everolimus & Pancreatic & $5 \% \mathrm{PR}, 73 \% \mathrm{SD}$ & 11.4 \\
\hline (RADIANT-3) & & Placebo & & $2 \% \mathrm{PR}, 5 \mathrm{I} \% \mathrm{SD}$ & 5.4 \\
\hline Yao et $\mathrm{al}^{47}$ & 302 & Everolimus & Nonfunctional Gl, lung or & $2 \% \mathrm{PR}, 8 \mathrm{I} \% \mathrm{SD}$ & 11 \\
\hline (RADIANT-4) & & Placebo & unknown primary & I\% PR, 64\% SD & 3.9 \\
\hline
\end{tabular}

Abbreviations: GEP, gastroenteropancreatic; GI, gastrointestinal; NET, neuroendocrine tumor; PFS, progression-free survival; PR, partial response; RADIANT, RAD00I in Advanced Neuroendocrine Tumors; SD, stable disease.

Table 5 Adverse events associated with everolimus in Phase III trials

\begin{tabular}{|c|c|c|c|c|c|c|}
\hline \multirow[t]{2}{*}{ Adverse event } & \multicolumn{2}{|l|}{ RADIANT-2 ${ }^{42}$} & \multicolumn{2}{|l|}{ RADIANT- $3^{44}$} & \multicolumn{2}{|l|}{ RADIANT-4 ${ }^{47}$} \\
\hline & All grades (\%) & Grades 3-4 (\%) & All grades (\%) & Grades 3-4 (\%) & All grades (\%) & All grades (\%) \\
\hline Stomatitis & 62 & 7 & 64 & 7 & 63 & 9 \\
\hline Rash & 37 & 1 & 49 & $<1$ & 27 & $<1$ \\
\hline Diarrhea & 27 & 6 & 34 & 3 & 31 & 3 \\
\hline Fatigue & 31 & 7 & 31 & 2 & 31 & 2 \\
\hline Infections & 20 & 5 & 23 & 2 & 29 & 7 \\
\hline Nausea & 20 & $<1$ & 20 & 2 & 17 & 2 \\
\hline Peripheral edema & 13 & 0 & 20 & $<1$ & 26 & 2 \\
\hline Decreased appetite & 13 & 0 & 20 & 0 & 16 & $<1$ \\
\hline Headache & - & - & 19 & 0 & - & - \\
\hline Dysgeusia & 17 & $<1$ & 17 & 0 & 15 & $<1$ \\
\hline Anemia & 15 & 1 & 17 & 6 & 16 & 4 \\
\hline Epistaxis & - & - & 17 & 0 & - & - \\
\hline Pneumonitis & 8 & - & 17 & 2 & 16 & 1 \\
\hline Weight loss & 15 & $<1$ & 16 & 0 & - & - \\
\hline Vomiting & II & $<1$ & 15 & 0 & - & - \\
\hline Pruritus & 11 & 0 & 15 & 0 & 13 & $<1$ \\
\hline Hyperglycemia & 15 & 5 & 13 & 5 & 10 & 3 \\
\hline Thrombocytopenia & 14 & 5 & 13 & 4 & - & - \\
\hline Asthenia & 10 & I & 13 & 1 & 16 & 2 \\
\hline Nail disorder & - & - & 12 & $<1$ & - & - \\
\hline Cough & - & - & 11 & 0 & 13 & 0 \\
\hline
\end{tabular}

Note: Dash indicates not reported.

Abbreviation: RADIANT, RAD00I in Advanced Neuroendocrine Tumors. 
by Panzuto et $\mathrm{al}^{48}$ that analyzed 169 patients with NETs included in a compassionate use program (CUP). Overall, $85 \%$ of patients experienced adverse events, which were severe (grades 3-4) in 46\%. During a median follow-up period of 12 months, the mortality rate was $28 \%$. In total, 17 deaths occurred during everolimus treatment, none of which were directly attributed to the drug. There were some differences in safety profiles compared with the toxicity observed in the pivotal trials. Common adverse events observed in patients enrolled in the RADIANT trials, such as stomatitis, rash and diarrhea, were more rarely reported in this study. On the contrary, a higher number of thrombocytopenia (22\%), renal failure (overall 17\%, 3.5\% grades $3-4)$ and severe pneumonitis ( $8 \%$ grades $3-4)$ events were observed in this study. The differences may be related to several factors, including a lower awareness of physicians who participated in the CUP of reporting mild toxicities, the retrospective nature of the study and the treatment administered before everolimus (PRRT in $50 \%$ of patients, chemotherapy in $50 \%$, both treatments in $23 \%$ ). The risk of any severe toxicity was in fact increased 12 -fold in patients who had received both PRRT and chemotherapy prior to everolimus ( $87 \%$ of these patients, compared with $34 \%$ of other patients). However, a retrospective evaluation of the safety profile of everolimus in 24 patients with GEP NETs previously treated with ${ }^{177} \mathrm{Lu}$-octreotate radionuclide therapy showed a safety profile consistent with the known safety profile of everolimus established in RADIANT trials. ${ }^{49}$ Previous findings suggest that caution should be exercised when using this drug in pretreated patients and raise the issue of planning for everolimus before PRRT and chemotherapy in the therapeutic strategy for advanced NETs. ${ }^{48}$

In addition to toxicity, in an often indolent or slowly progressive disease such as NETs, it is important to focus on QoL, which is a key factor in determining treatment options. However, there was a lack of extensive QoL information in NETs as the Phase III trials, RADIANT-2 and RADIANT-3, did not collect QoL data. In contrast to the previous trials, RADIANT-4 has measured QoL using a FACT-G (Functional Assessment of Cancer Therapy - General) questionnaire. In this study, the time to deterioration in FACT-G has been not significantly different in the two arms. ${ }^{50,51}$ There are also recent data published about QoL in patients on everolimus from an expanded access program involving 246 patients with NETs, where authors concluded that QoL remains stable throughout everolimus therapy. It is imperative that further trials in NETs include QoL data since they have become an important end point in clinical research to evaluate patients' wellness. ${ }^{52-56}$

\section{Role of everolimus in the daily life; can we expect the same activity in the "real world"?}

The efficacy of everolimus in patients with NETs has also been analyzed in the real-word setting in a retrospective analysis conducted by Panzuto et al. ${ }^{48} \mathrm{~A}$ total of 169 patients with advanced progressive NETs (85 with pNETs and 84 with non-pNETs) were treated with everolimus in a CUP. Patients' characteristics were similar to the pivotal trials. The study showed superimposable results to the registration studies, achieving tumor control in $76 \%$ patients, with SD in $68 \%$ and PR in $7.7 \%$ of patients. Median PFS was 12 months, with similar values in patients with pNETs and non-pNETs (11 and 12 months, respectively). Median OS was 32 months. Interestingly, the Ki-67 value of $12 \%$ was identified as a better cutoff between responders and nonresponders. A second study with 44 GEP-NET patients treated with everolimus or sunitinib confirmed these data in the real-world setting. PFS with everolimus was 16.6 and 14.7 months in pNETs and gastrointestinal NETs, respectively. ${ }^{57}$

\section{Combinations and ongoing trials of everolimus}

mTOR inhibitors produce mostly disease stabilization rather than tumor regression. Thereafter, there have been many attempts to combine mTOR-targeted therapies with other drugs to cause a cytotoxic effect rather than cytostatic response to produce tumor mass regressions.

It is known that rapalogs inhibit mTOR activity but induce upstream signaling, leading to Akt activation, potentially limiting antitumor activity. It has been observed that SSAs decrease PI3K/Akt signaling pathway in some models, and thus SSAs may theoretically enhance the antitumor activity of rapalogs. However, preclinical models have not clearly confirmed this synergy and clinical trials have shown discordant results. The previously mentioned Phase II trial of everolimus in combination with octreotide conducted by Yao et $\mathrm{al}^{40}$ demonstrated promising clinical efficacy with an ORR of $22 \%{ }^{58}$ In RADIANT-1, the combination of everolimus and octreotide seemed to result in a longer PFS than everolimus alone. Nevertheless, this result, as previously mentioned, may also be attributable to differences between patient cohorts. ${ }^{41}$ Promising results from RADIANT-1 led to the subsequent Phase III RADIANT-2, where the addition of octreotide LAR to everolimus led to a trend toward improved PFS over octreotide alone, but without meeting the prespecified threshold for statistical significance. In fact, the Phase II 
COOPERATE-2 trial evaluating everolimus with or without the SSA pasireotide in 160 patients with pNETs showed no significant increase in PFS with the addition of pasireotide to everolimus (PFS: 16.8 months with pasireotide compared with 16.6 months in patients treated with everolimus alone). ${ }^{59}$ Subsequent studies, RADIANT-3 and RADIANT-4 trials, did not allow treatment with SSAs. Although the combination is well tolerated, the mentioned trials have caused much debate as to antineoplastic efficacy of the combination over either of the drugs alone. ${ }^{42,44,47}$

Both VEGFR and mTOR inhibitors are active in NETs; thus, the combination of these agents is another possible synergistic strategy. Chan et $\mathrm{al}^{39}$ evaluated the combination of everolimus and sorafenib in a Phase I trial of patients with advanced NET. While the combination seemed to be active ( $62 \%$ of patients had some degree of tumor shrinkage), toxicity concerns may preclude more widespread use. The combination of everolimus with bevacizumab may represent an alternative and potentially a more tolerable approach. This combination has also been found to be well tolerated and associated with antitumor activity in a single-arm Phase II study of patients with NETs conducted by Yao et al. ${ }^{60}$ In another trial, CALGB 80701, a randomized Phase II study, the efficacy of everolimus versus everolimus plus bevacizumab was assessed in 150 patients with advanced pNETs. Treatment with both agents resulted in significantly higher response rates ( 31 versus $12 \% ; p=0.005$ ) and a slight increase in PFS (16.7 versus 14 months; HR: 0.80; $p=0.12$ ). However, more adverse events were detected in the combination group, including hypertension (38\% grades 3-4 compared with $8 \%$ of the monotherapy arm), proteinuria (16\% versus $1 \%$ ), diarrhea (11\% versus $1 \%)$ and hypophosphatemia (10\% versus $1 \%$ ). The frequency of grade 4 adverse events was $11 \%$ in both arms. ${ }^{61}$ These results support the potential biological activity of the combination, but additional Phase III trials should be pursued to further confirm the benefit of everolimus and bevacizumab in NETs.

There are a growing number of ongoing studies that are evaluating other agents alone or in combination with everolimus in patients with NETs (Table 6). As NETs are highly vascularized tumors, some of these drugs target vascular pathways. Fosbretabulin, a potent tubulin-binding vascular disrupting agent, exerts its antitumor effect targeting blood vessels. X-82 and vatalanib are two orally available molecules that target VEGFRs and platelet-derived growth factor receptors. ${ }^{62-65}$ There are also trials with agents targeting components of the mTOR pathway or other pathways that lead to mTOR activation, trying to overcome tumor escape mechanisms. Some examples are cixutumumab and R1507, two fully humanized monoclonal antibodies that target IGF receptor 1; erlotinib, an EGFR inhibitor that may abrogate feedback loops that stimulate upstream signaling events such as PI3K and Akt in the context of mTOR inhibition; alpelisib, a selective oral inhibitor of the class I PI3K catalytic subunit p110 $\alpha$; BEZ235, a dual PI3K/mTOR inhibitor and sapanisertib that blocks both mTORC1 and mTORC2. ${ }^{65-69}$ Other combination therapy examples with everolimus include SNX-5422, a heat shock protein 90 inhibitor, or chemotherapy such as temozolomide, streptozotocin (STZ) or 5-fluorouracil (5-FU). ${ }^{70}$

Table 6 Ongoing trials in patients with NETs

\begin{tabular}{|c|c|c|c|c|}
\hline Agents & Tumor & Phase & Status & Trial identifier \\
\hline Everolimus + fosbretabulin & GEP NENs (grades I-3) & 1 & Not yet opened & NCT030I4297 \\
\hline Cixutumumab + everolimus + octreotide & $\begin{array}{l}\text { NETs of different } \\
\text { anatomic sites }\end{array}$ & I & Completed & NCT0I 204476 \\
\hline VEGFR/PDGFR dual kinase inhibitor X-82 + everolimus & pNETs & I-II & Recruiting participants & NCT0I78486I \\
\hline SNX-5422 + everolimus & $\begin{array}{l}\text { NETs of different } \\
\text { anatomic sites }\end{array}$ & I & $\begin{array}{l}\text { Ongoing, but not recruiting } \\
\text { participants }\end{array}$ & NCT02063958 \\
\hline $\begin{array}{l}\text { Everolimus/STZ-5-FU Given One Upfront the Other } \\
\text { (SEQTOR) }\end{array}$ & PNET & III & $\begin{array}{l}\text { Ongoing, but not recruiting } \\
\text { participants }\end{array}$ & NCT02246I 27 \\
\hline $\begin{array}{l}\text { Alpelisib + everolimus/alpelisib + everolimus + } \\
\text { exemestane }\end{array}$ & $\begin{array}{l}\text { Breast cancer } \\
\text { Renal cell cancer } \\
\text { Pancreatic tumors }\end{array}$ & I & $\begin{array}{l}\text { Ongoing, but not recruiting } \\
\text { participants }\end{array}$ & NCT02077933 \\
\hline Erlotinib + everolimus & $\begin{array}{l}\text { NETs of different } \\
\text { anatomic sites }\end{array}$ & II & Unknown & NCT00843531 \\
\hline RI507 + everolimus & Solid tumors & lb-II & Completed & NCT00985374 \\
\hline Vatalanib + everolimus & Solid tumors & I & $\begin{array}{l}\text { Ongoing, but not recruiting } \\
\text { participants }\end{array}$ & NCT00655655 \\
\hline
\end{tabular}

Abbreviations: 5-FU, 5-fluorouracil; GEP, gastroenteropancreatic; NENs, neuroendocrine neoplasms; NET, neuroendocrine tumor; pNET, pancreatic NET; STZ, streptozotocin. 


\section{Conclusion: place in therapy}

Several therapeutic options are now available for NET patients. Although the incidence of these tumors is increasing, NETs have been usually considered a rare entity. Prospective randomized trials, mostly for surgical treatment, ablative therapies and chemotherapy have been limited. In the past years, SSA, novel targeted drugs, such as everolimus and sunitinib, and PPRT have been evaluated versus placebo controlled in randomized Phase III trials in NETs. These trials have an impact on the current treatment recommendations in NETs; however, comparative clinical trials between all these options are still lacking and the different therapies cannot be placed in a specific sequence. Given the variety of treatment choices and the heterogeneity of NETs, it is strongly recommended to discuss NET patients in a multidisciplinary tumor board. Therapeutic decision-making will depend on the primary tumor site, its functional status, its rate of growth, grade, presence of extrahepatic disease, overall tumor burden and patient's comorbidities. Important considerations in the treatment of these indolent tumors should be the avoidance of toxicity and the maintenance of good QoL.

Generally, target therapy is used in most patients with advanced NETs after progression on SSAs. Everolimus has demonstrated an improvement in PFS in two randomized Phase III trials, RADIANT-3 and RADIANT-4, in patients with pNET and nonfunctional NETs of gastrointestinal, lung or unknown primary origin, respectively. In these studies, prespecified subgroup analyses showed that the benefit was maintained across subgroups, irrespective of prior therapy, performance status, age, sex, race, tumor grade and primary tumor origin. While everolimus is approved for these indications, sunitinib is only approved in progressive pNET, and Lu-Dototate has shown benefit limited to midgut NETs. In addition, everolimus has shown benefit in a CUP in the real-world setting.

It is a common practice to combine everolimus with SSA in functionally active NETs. There might also be a rationale for this combination in nonfunctioning NETs given the high frequency of expression of somatostatin receptors; however, there is no clear evidence that the combination therapy of everolimus and SSA is superior to monotherapy with everolimus for antiproliferative purposes, and therefore the combination therapy cannot be recommended in nonfunctioning tumors. Side effects of everolimus are in general mild and include most frequently stomatitis, rash, diarrhea and fatigue. Another potential side effect is pneumonitis, although infrequent, it can be a more worrying toxicity and careful surveillance is required.

Everolimus has been robustly established as a welltolerable and effective treatment option in NETs. However, many questions remain, including the optimal combinations with other target agents intersecting cellular pathways, as well as sequencing strategies. Deeper understanding of the molecular landscape of NETs could help to find a biomarker to predict the efficacy of different available treatment options and also to draw the best treatment strategy for each individual patient.

\section{Disclosure}

EG has served as advisor and delivered lectures for Novartis, Pfizer and IPSEN. PG, OMS and TAG report no conflicts of interest in this work.

\section{References}

1. Yao JC, Hassan M, Phan A, et al. One hundred years after "carcinoid": epidemiology of and prognostic factors for neuroendocrine tumors in 35,825 cases in the United States. J Clin Oncol. 2008;26(18):3063-3072.

2. Phan AT, Oberg K, Choi J, et al. NANETS consensus guideline for the diagnosis and management of neuroendocrine tumors: welldifferentiated neuroendocrine tumors of the thorax (includes lung and thymus). Pancreas. 2010;39(6):784-798.

3. Klimstra DS, Modlin IR, Coppola D, Lloyd RV, Suster S. The pathologic classification of neuroendocrine tumors: a review of nomenclature, grading, and staging systems. Pancreas. 2010;39(6):707-712.

4. Bosman FT; World Health Organization, International Agency for Research on Cancer. editors. WHO Classification of Tumours of the Digestive System. 4th ed. Lyon: IARC Press; 2010:417.

5. Rindi G, Klöppel G, Couvelard A, et al. TNM staging of midgut and hindgut (neuro) endocrine tumors: a consensus proposal including a grading system. Virchows Arch. 2007;451(4):757-762.

6. Rindi G, Klöppel G, Alhman H, et al. TNM staging of foregut (neuro) endocrine tumors: a consensus proposal including a grading system. Virchows Arch. 2006;449(4):395-401.

7. Travis WD, Brambilla E, Nicholson AG, et al. The 2015 World Health Organization classification of lung tumors. J Thorac Oncol. 2015;10(9):1243-1260.

8. Caplin ME, Baudin E, Ferolla P, et al; ENETS Consensus Conference Participants. Pulmonary neuroendocrine (carcinoid) tumors: European Neuroendocrine Tumor Society expert consensus and recommendations for best practice for typical and atypical pulmonary carcinoids. Ann Oncol. 2015;26(8):1604-1620.

9. Eriksson J, Stålberg P, Nilsson A, et al. Surgery and radiofrequency ablation for treatment of liver metastases from midgut and foregut carcinoids and endocrine pancreatic tumors. World J Surg. 2008;32(5):930-938.

10. Mazzaglia PJ, Berber E, Milas M, Siperstein AE. Laparoscopic radiofrequency ablation of neuroendocrine liver metastases: a 10-year experience evaluating predictors of survival. Surgery. 2007;142(1):10-19.

11. Modlin IM, Oberg K, Chung DC, et al. Gastroenteropancreatic neuroendocrine tumours. Lancet Oncol. 2008;9(1):61-72.

12. Roviello G, Zanotti L, Venturini S, Bottini A, Generali D. Role of targeted agents in neuroendocrine tumors: results from a meta-analysis. Cancer Biol Ther. 2016;17(9):883-888.

13. Pavel M, Baudin E, Couvelard A, et al. ENETS consensus guidelines for the management of patients with liver and other distant metastases from neuroendocrine neoplasms of foregut, midgut, hindgut, and unknown primary. Neuroendocrinology. 2012;95(2):157-176.

14. Rinke A, Wittenberg M, Schade-Brittinger C, et al; PROMID Study Group. Placebo-controlled, double-blind, prospective, randomized study on the effect of octreotide LAR in the control of tumor growth in patients with metastatic neuroendocrine midgut tumors (PROMID): results of long-term survival. Neuroendocrinology. 2017;104(1):26-32.

15. Strosberg J, El-Haddad G, Wolin E, et al. Phase 3 trial of (177) Lu-Dotatate for midgut neuroendocrine tumors. $N$ Engl J Med. 2017;376(2):125-135. 
16. Berardi R, Rinaldi S, Torniai M, et al. Gastrointestinal neuroendocrine tumors: searching the optimal treatment strategy - a literature review. Crit Rev Oncol Hematol. 2016;98:264-274.

17. Smrz D, Kim M-S, Zhang S, et al. mTORC1 and mTORC2 differentially regulate homeostasis of neoplastic and non-neoplastic human mast cells. Blood. 2011;118(26):6803-6813.

18. Sarbassov DD, Guertin DA, Ali SM, Sabatini DM. Phosphorylation and regulation of Akt/PKB by the rictor-mTOR complex. Science. 2005;307(5712):1098-1101.

19. Meric-Bernstam F, Gonzalez-Angulo AM. Targeting the mTOR signaling network for cancer therapy. J Clin Oncol. 2009;27(13):2278-2287.

20. Zhou BP, Hu MC, Miller SA, et al. HER-2/neu blocks tumor necrosis factor-induced apoptosis via the Akt/NF-kappaB pathway. J Biol Chem. 2000;275(11):8027-8031.

21. Chung J, Bachelder RE, Lipscomb EA, Shaw LM, Mercurio AM. Integrin (alpha 6 beta 4) regulation of eIF-4E activity and VEGF translation: a survival mechanism for carcinoma cells. J Cell Biol. 2002;158(1):165-174.

22. Cui X, Zhang P, Deng W, et al. Insulin-like growth factor-I inhibits progesterone receptor expression in breast cancer cells via the phosphatidylinositol 3-kinase/Akt/mammalian target of rapamycin pathway: progesterone receptor as a potential indicator of growth factor activity in breast cancer. Mol Endocrinol. 2003;17(4):575-588.

23. Stemke-Hale K, Gonzalez-Angulo AM, Lluch A, et al. An integrative genomic and proteomic analysis of PIK3CA, PTEN, and AKT mutations in breast cancer. Cancer Res. 2008;68(15):6084-6091.

24. O'Donnell A, Faivre S, Burris HA, et al. Phase I pharmacokinetic and pharmacodynamic study of the oral mammalian target of rapamycin inhibitor everolimus in patients with advanced solid tumors. J Clin Oncol. 2008;26(10):1588-1595.

25. Wullschleger S, Loewith R, Hall MN. TOR signaling in growth and metabolism. Cell. 2006;124(3):471-484.

26. Roux PP, Ballif BA, Anjum R, Gygi SP, Blenis J. Tumor-promoting phorbol esters and activated Ras inactivate the tuberous sclerosis tumor suppressor complex via p90 ribosomal S6 kinase. Proc Natl Acad Sci US A. 2004;101(37):13489-13494.

27. Phung TL, Ziv K, Dabydeen D, et al. Pathological angiogenesis is induced by sustained Akt signaling and inhibited by rapamycin. Cancer Cell. 2006;10(2):159-170.

28. Flaum N, Valle JW, Mansoor W, McNamara MG. Everolimus in the treatment of neuroendocrine tumors of the respiratory and gastroenteropancreatic systems. Future Oncol. 2016;12(22):2561-2578.

29. Houghton PJ. Everolimus. Clin Cancer Res. 2010;16(5):1368-1372.

30. Kirchner GI, Meier-Wiedenbach I, Manns MP. Clinical pharmacokinetics of everolimus. Clin Pharmacokinet. 2004;43(2):83-95.

31. Jacobsen W, Serkova N, Hausen B, Morris RE, Benet LZ, Christians U. Comparison of the in vitro metabolism of the macrolide immunosuppressants sirolimus and RAD. Transplant Proc. 2001;33(1-2): 514-515.

32. Levy GA, Grant D, Paradis K, Campestrini J, Smith T, Kovarik JM. Pharmacokinetics and tolerability of 40-0-[2-hydroxyethyl]rapamycin in de novo liver transplant recipients. Transplantation. 2001;71(1):160-163.

33. Bushnell DL, O’Dorisio TM, O’Dorisio MS, et al. 90Y-edotreotide for metastatic carcinoid refractory to octreotide. J Clin Oncol. 2010;28(10): 1652-1659.

34. Easton JB, Houghton PJ. mTOR and cancer therapy. Oncogene. 2006;25(48):6436-6446.

35. Beuvink I, Boulay A, Fumagalli S, et al. The mTOR inhibitor RAD001 sensitizes tumor cells to DNA-damaged induced apoptosis through inhibition of p21 translation. Cell. 2005;120(6):747-759.

36. Boulay A, Rudloff J, Ye J, et al. Dual inhibition of mTOR and estrogen receptor signaling in vitro induces cell death in models of breast cancer. Clin Cancer Res. 2005;11(14):5319-5328.

37. Missiaglia E, Dalai I, Barbi S, et al. Pancreatic endocrine tumors: expression profiling evidences a role for AKT-mTOR pathway. J Clin Oncol. 2010;28(2):245-255.
38. Chan JA, Ryan DP, Zhu AX, et al. Phase I study of pasireotide (SOM 230) and everolimus (RAD001) in advanced neuroendocrine tumors. Endocr Relat Cancer. 2012;19(5):615-623.

39. Chan JA, Mayer RJ, Jackson N, Malinowski P, Regan E, Kulke MH. Phase I study of sorafenib in combination with everolimus (RAD001) in patients with advanced neuroendocrine tumors. Cancer Chemother Pharmacol. 2013;71(5):1241-1246.

40. Yao JC, Phan AT, Chang DZ, et al. Efficacy of RAD001 (everolimus) and octreotide LAR in advanced low- to intermediate-grade neuroendocrine tumors: results of a phase II study. J Clin Oncol. 2008;26(26): 4311-4318.

41. Yao JC, Lombard-Bohas C, Baudin E, et al. Daily oral everolimus activity in patients with metastatic pancreatic neuroendocrine tumors after failure of cytotoxic chemotherapy: a phase II trial. J Clin Oncol. 2010;28(1) 69-76.

42. Pavel ME, Hainsworth JD, Baudin E, et al; RADIANT-2 Study Group. Everolimus plus octreotide long-acting repeatable for the treatment of advanced neuroendocrine tumours associated with carcinoid syndrome (RADIANT-2): a randomised, placebo-controlled, phase 3 study. Lancet. 2011;378(9808):2005-2012.

43. Anthony LB, Pavel ME, Hainsworth JD, et al. Impact of previous somatostatin analogue use on the activity of everolimus in patients with advanced neuroendocrine tumors: analysis from the phase III RADIANT-2 trial. Neuroendocrinology. 2015;102(1-2):18-25.

44. Yao JC, Shah MH, Ito T, et al; RAD001 in Advanced Neuroendocrine Tumors, Third Trial (RADIANT-3) Study Group. Everolimus for advanced pancreatic neuroendocrine tumors. $N$ Engl J Med. 2011;364(6):514-523

45. Yao JC, Pavel M, Lombard-Bohas C, et al. Everolimus for the treatment of advanced pancreatic neuroendocrine tumors: overall survival and circulating biomarkers from the randomized, phase III RADIANT-3 Study. J Clin Oncol. Epub 2016 Sep 12.

46. National Cancer Institute [webpage on the Internet]. FDA Approval for Everolimus. National Cancer Institute [cited January 17, 2017] Available from: https://www.cancer.gov/about-cancer/treatment/drugs/ fda-everolimus. Accessed May 22, 2017.

47. Yao JC, Fazio N, Singh S, et al; RAD001 in Advanced Neuroendocrine Tumours, Fourth Trial (RADIANT-4) Study Group. Everolimus for the treatment of advanced, non-functional neuroendocrine tumours of the lung or gastrointestinal tract (RADIANT-4): a randomised, placebocontrolled, phase 3 study. Lancet. 2016;387(10022):968-977.

48. Panzuto F, Rinzivillo M, Fazio N, et al. Real-world study of everolimus in advanced progressive neuroendocrine tumors. Oncologist. 2014;19(9):966-974.

49. Kamp K, Gumz B, Feelders RA, et al. Safety and efficacy of everolimus in gastrointestinal and pancreatic neuroendocrine tumors after $177 \mathrm{Lu}-$ octreotate. Endocr Relat Cancer. 2013;20(6):825-831.

50. Pavel ME, Strosberg JR, Bubuteishvili-Pacaud L, et al. Health-related quality of life (HRQoL) in patients with advanced, nonfunctional, well-differentiated gastrointestinal (GI) or lung neuroendocrine tumors (NET) in the phase 3 RADIANT-4 trial. $J$ Clin Oncol. 2016;34:sul;abstre15657.

51. Singh S, Strosberg JR, Bubuteishvili-Pacaud L, et al. Health-related quality of life (HRQoL) in patients with advanced neuroendocrine tumors (NET) of gastrointestinal origin in the phase 3 RADIANT-4 trial. J Clin Oncol. 2017;35:sul4S;abstract285.

52. Jiménez-Fonseca P, Carmona-Bayonas A, Martín-Pérez E, et al; Spanish Neuroendocrine Tumor Group (GETNE). Health-related quality of life in well-differentiated metastatic gastroenteropancreatic neuroendocrine tumors. Cancer Metastasis Rev. 2015;34(3):381-400.

53. Chan DL, Segelov E, Singh S. Everolimus in the management of metastatic neuroendocrine tumours. Ther Adv Gastroenterol. 2017;10(1):132-141.

54. Burris HA, Lebrun F, Rugo HS, et al. Health-related quality of life of patients with advanced breast cancer treated with everolimus plus exemestane versus placebo plus exemestane in the phase 3, randomized, controlled, BOLERO-2 trial. Cancer. 2013;119(10):1908-1915. 
55. Motzer RJ, Escudier B, Oudard S, et al. Efficacy of everolimus in advanced renal cell carcinoma: a double-blind, randomised, placebocontrolled phase III trial. Lancet Lond Engl. 2008;372(9637):449-456.

56. Pavel M, Unger N, Borbath I, et al. Safety and QOL in patients with advanced NET in a phase $3 \mathrm{~b}$ expanded access study of everolimus. Target Oncol. 2016;11(5):667-675.

57. Yoo C, Cho H, Song MJ, et al. Efficacy and safety of everolimus and sunitinib in patients with gastroenteropancreatic neuroendocrine tumor. Cancer Chemother Pharmacol. 2017;79(1):139-146.

58. Moreno A, Akcakanat A, Munsell MF, Soni A, Yao JC, Meric-Bernstam F. Antitumor activity of rapamycin and octreotide as single agents or in combination in neuroendocrine tumors. Endocr Relat Cancer. 2008;15(1):257-266.

59. Kulke M, Ruszniewski P, van Cutsem E, et al. A randomized openlabel phase II study of everolimus alone or in combination with pasireotide LAR in advanced, progressive pancreatic neuroendocrine tumors (pNET): COOPERATE-2 trial. Presented at the 12th Annual ENETS conference for the Diagnosis and Treatment of Neuroendocrine Tumor Disease; Barcelona; 2015. Neuroendocrinology; 102:131.

60. Yao JC, Phan AT, Fogleman D, et al. Randomized run-in study of bevacizumab (B) and everolimus (E) in low- to intermediate-grade neuroendocrine tumors (LGNETs) using perfusion CT as functional biomarker. J Clin Oncol. 2010;28:15s(sul;abstr4002).

61. Kulke MH, Niedzwiecki D, Foster NR, et al. Randomized phase II study of everolimus (E) versus everolimus plus bevacizumab (E+B) in patients (Pts) with locally advanced or metastatic pancreatic neuroendocrine tumors (pNET), CALGB 80701 (Alliance). J Clin Oncol. 2015;33:sul;abstr4005.

62. Young SL, Chaplin DJ. Combretastatin A4 phosphate: background and current clinical status. Expert Opin Investig Drugs. 2004;13(9): 1171-1182.

63. Wood JM, Bold G, Buchdunger E, et al. PTK787/ZK 222584, a novel and potent inhibitor of vascular endothelial growth factor receptor tyrosine kinases, impairs vascular endothelial growth factor-induced responses and tumor growth after oral administration. Cancer Res. 2000;60(8):2178-2189.
64. Xcovery. Xcovery-Presents-Phase-1-Clinical-Results-at-ASCO [cited January 26, 2017]. Available from: https://www.xcovery.com/wordpress/ wp-content/uploads/Xcovery-Presents-Phase-1-Clinical-Results-atASCO.pdf. Accessed May 22, 2017.

65. Furet P, Guagnano V, Fairhurst RA, et al. Discovery of NVP-BYL719 a potent and selective phosphatidylinositol-3 kinase alpha inhibitor selected for clinical evaluation. Bioorg Med Chem Lett. 2013;23(13): 3741-3748.

66. McKian KP, Haluska P. Cixutumumab. Expert Opin Investig Drugs. 2009;18(7):1025-1033.

67. OSI Pharmaceuticals, LLC. Tarceva (erlotinib) tablets [product information]. Farmingdale, NY: OSI Pharmaceuticals, LLC, an affiliate of Astellas Pharma US Inc; 2012.

68. Maira S-M, Stauffer F, Brueggen J, et al. Identification and characterization of NVP-BEZ235, a new orally available dual phosphatidylinositol 3-kinase/mammalian target of rapamycin inhibitor with potent in vivo antitumor activity. Mol Cancer Ther. 2008;7(7):1851-1863.

69. Hassan B, Akcakanat A, Sangai T, et al. Catalytic mTOR inhibitors can overcome intrinsic and acquired resistance to allosteric mTOR inhibitors. Oncotarget. 2014;5(18):8544-8557.

70. Fadden P, Huang KH, Veal JM, et al. Application of chemoproteomics to drug discovery: identification of a clinical candidate targeting hsp90. Chem Biol. 2010;17(7):686-694.

71. Caplin ME, Pavel M, Ćwikła JB, et al. Lanreotide in metastatic enteropancreatic neuroendocrine tumors. NEngl J Med. 2014;371(3):224-233.

72. Raymond E, Dahan L, Raoul J-L, et al. Sunitinib malate for the treatment of pancreatic neuroendocrine tumors. $N$ Engl $J$ Med. 2011;364(6):501-513.

73. Sun W, Lipsitz S, Catalano P, Mailliard JA, Haller DG; Eastern Cooperative Oncology Group. Phase II/III study of doxorubicin with fluorouracil compared with streptozocin with fluorouracil or dacarbazine in the treatment of advanced carcinoid tumors: Eastern Cooperative Oncology Group Study E1281. J Clin Oncol. 2005;23(22):4897-4904.

74. Ferolla P, Brizzi MP, Meyer T, et al. Efficacy and safety of pasireotide LAR or everolimus alone, or in combination in patients with advanced carcinoids (NET) of the lung/thymus: results from the randomized, phase 2 LUNA study. Ann Oncol. 2016;27(suppl 6):416O.
Cancer Management and Research

\section{Publish your work in this journal}

Cancer Management and Research is an international, peer-reviewed open access journal focusing on cancer research and the optimal use of preventative and integrated treatment interventions to achieve improved outcomes, enhanced survival and quality of life for the cancer patient. The manuscript management system is completely online and includes

\section{Dovepress}

a very quick and fair peer-review system, which is all easy to use. Visit http://www.dovepress.com/testimonials.php to read real quotes from published authors. 